\title{
Analisis Mutu Pelayanan Nifas Pertama (KF1) oleh Bidan di Puskesmas di Kabupaten Pemalang Tahun 2018
}

\author{
Ragil Sri Pamungkas*, Chriswardani Suryawati**, Apoina Kartini** \\ *Dinas Kesehatan Kabupaten Pemalang, \\ **Fakultas Kesehatan Masyarakat, Universitas Diponegoro, Semarang \\ Email :ragil.pamungkas28@yahoo.co.id
}

\section{ABSTARCT:}

Maternal Mortality Rate (MMR) in Pemalang Regency in 2017 is still high and happens a lot during childbirth time period (72\%). One of the efforts for reducing $M M R$ is the quality service of childbirth for the process of mother and baby recovery, early detection of complications, taking care of and referral of complications. The aim of the study is to determine and analyze the quality of the first childbirth service (KF1) and factors related to the service quality of first childbirth (KF1) by midwives at Health Centres in Pemalang Regency.

Quantitative research method used cross sectional research type, sample selection by simple random sampling at 100 civil servant of midwives working period of at least three years in 14 health centres in each sub-district in Pemalang Regency. Data collections were done by questionnaires and observations, data analysis with chi-square statistical tests and multivariate with multiple logistic regression.

Research results showed that the service quality of the first childbirth (KF1) is lacking (53\%), lacking motivation (54\%), less reward (65\%), less supervision (50\%) and workload according to the standard (57\%). Variables related to the service quality of the first childbirth (KF1) are motivation $(p$-value $=0.018)$ and rewards $(p$-value $=0.003)$. While the variables not related to the service quality of the first childbirth (KF1) are supervision (p-value $=0.229)$ and workload ( $p$-value $=0.774)$. The factors that influence the service quality of the first childbirth (KF1) are rewards (value $p=0.031$ and $O R=3,466$ ). Keyword : mutu pelayanan nifas, motivasi, beban kerja

\section{PENDAHULUAN}

Target yang telah ditentukan SDGs dalam 1,5 dekade ke depan mengenai angka kematian ibu (AKI) adalah penurunan AKI menjadi 70 per 100 ribu kelahiran hidup. AKI di Indonesia pada Tahun 2016 sebesar 305 per 100 ribu kelahiran hidup ${ }^{1}$, AKI di Provinsi Jawa Tengah pada tahun 2015 sebesar 111,16 per 100 ribu kelahiran hidup (619 kasus), dengan jumlah kematian ibu terjadi pada masa nifas sebanyak $60,90 \%$ (377 kasus). ${ }^{2}$ Tahun 2016 AKI menurun menjadi 109,65 per 100 ribu kelahiran hidup (602 kasus) dengan jumlah kematian ibu pada masa nifas sebanyak $63,12 \%$ (380 kasus). ${ }^{3}$

Di Kabupaten Pemalang pada Tahun 2015 AKI merupakan urutan ke lima di Jawa Tengah yaitu 32 kasus, 24 kasus terjadi pada masa nifas. ${ }^{4}$ Pada Tahun 2016 AKI menjadi urutan ke dua di Jawa Tengah, meningkat menjadi 45 kasus,kematian pada masa nifas sebanyak 34 kasus. ${ }^{5}$ Tahun 2017 AKI menjadi urutan 
ke tiga di Jawa Tengah dengan jumlah 25 kasus yang terjadi pada masa nifas sebanyak 18 kasus. $^{6}$ Dari 18 kasus kematian tersebut, 8 kasus diantaranya terjadi pada waktu 40 jam sampai dengan 3 hari setelah melahirkan yang merupakan masa pelayanan nifas pertama (KF1) dengan penyebab kematian antara lain : PEB, Hipertensi, Perdarahan, Jantung dan Emboli air ketuban. ${ }^{7}$

Dari data diatas menunjukkan angka kematian ibu di Kabupaten Pemalang masih jauh dari target SDGs dan kematian ibu terbanyak pada masa nifas. Hal ini seperti disampaikan oleh WHO bahwa masalah bisa terjadi pada masa nifas yang jika tidak ditangani dengan segera dan efektif dapat menyebabkan masalah kesehatan bahkan kematian bagi ibu maupun bayinya, namun perawatan nifas sering diabaikan padahal secara fakta mayoritas kematian ibu dan kecacatan terjadi pada masa nifas dan kematian bayi juga tinggi. ${ }^{8}$ Sebagaimana penelitian yang dilakukan oleh Khamidah Achyar, dkk bahwa kasus kematian pada masa nifas di Kabupaten Banyumas meningkat setiap tahun disebabkan komplikasi yang terjadi pada masa nifas. ${ }^{9}$ Perhatian untuk meningkatkan kesehatan ibu pada masa nifas antara lain dengan pelaksanaan pelayanan ibu nifas yaitu pelayanan kesehatan yang diberikan kepada ibu mulai dari 6 jam sampai dengan 42 hari setelah melahirkan sesuai standar oleh tenaga kesehatan. Pelayanan nifas minimal 3 (tiga) kali yaitu kunjungan nifas yang pertama (KF1) pada waktu 6 jam setelah melahirkan sampai 3 hari, kunjungan nifas kedua (KF2) dalam waktu 2 (dua) minggu setelah melahirkan (8-14 hari) dan kunjungan nifas ketiga (KF3) dalam waktu 6 (enam) minggu post partum (3642 hari $)^{10}$. Pelayanan kesehatan bagi ibu dan bayi dalam masa nifas dilakukan untuk membantu proses ibu dan bayi dalam proses pemulihan, penjelasan mengenai perawatan pada tali pusat, deteksi dini kejadian abnormal masa nifas, penanganan dan rujukan terhadap kejadian tak diinginkan yang bisa terjadi, kesehatan secara umum, kebersihan individu, kebutuhan gizi, perawatan bayi, pemberian ASI, imunisasi dan KB. ${ }^{11}$

Mutu pelayanan dasar yang harus diberikan pemerintah kepada masyarakat dapat dilihat dari capaian SPM yang merupakan pencapaian target sebagai hasil kinerja pemerintah maka harus 100\% setiap tahunnya. ${ }^{12}$ SPM bidang kesehatan untuk pelayanan ibu nifas ditunjukkan dengan cakupan pelayanan nifas, Di Kabupaten Pemalang berturut-turut dari Tahun 2015 sampai dengan Tahun 2017 yaitu sebesar $99,12 \%^{4}, \quad 98,88 \% \%^{5}$ dan $92,38 \% \%^{7}$. Cakupan pelayanan nifas dalam 3 (tiga) tahun ini mengalami penurunan dan masih dibawah target SPM Nasional yaitu sebesar $100 \%$. Pelayanan kesehatan bermutu adalah pelayanan kesehatanyang dilaksanakan sesuai kriteria dan standar profesional terkini yang memenuhi kebutuhan dan keinginan pelanggan secara efisien dan optimal ${ }^{13}$. Dalam pengukuran mutu langkah-langkah yang perlu dilakukan yaitu membentuk tim jaminan mutu layanan kesehatan, penyusunan standar layanan kesehatan, pemilihan teknik dalam pengukuran mutu untuk mengevaluasi mutu layanan kesehatan yang dilaksanakan serta membandingkan kenyataan yang terjadi disesuaikan standar pelayananan kesehatan yang disepakati. ${ }^{14}$

Untuk dapat melaksanakan pelayanan nifas yang bermutu dan berkualitas, maka perlu melakukan peningkatan standar menjaga mutu sebagai acuan dalam memperbaiki dan meningkatkan kinerja pelayanan nifas oleh bidan. Kinerja adalah hasil kerja secara kualitas dan kuantitas yang dicapai oleh seseorang dalam melaksanakan tugas sesuai tanggung jawab yang diberikan. ${ }^{15}$

Berdasarkan teori Gibson bahwa ada tiga variabel yang dapat mempengaruhi perilaku dan kinerja yaitu variabel individu terdiri dari kemampuan dan keterampilan, latar belakang serta demografi, variabel psikologis yang terdiri dari persepsi, sikap, kepribadian, belajar 
dan motivasi, serta variabel organisasi yang terdiri SDM, kepemimpinan, imbalan, struktur, supervisi, beban kerja dan desain pekerjaan. Output yang diharapkan dari setiap perilaku adalah prestasi dalam melaksanakan pekerjaan sehingga pelayanan yang diberikan bermutu. ${ }^{16}$

Di Kabupaten Pemalang pelayanan nifas di puskesmas dilaksanakan oleh semua bidan yang bertugas di ruang KIAKB dan ruang bersalin, baik didalam gedung maupun luar gedung berdasarkan Standar Operasional Prosedur (SOP) yang ada. Kebijakan pelayanan nifas dilaksanakan sebanyak tiga kali, yaitu pelayanan nifas pertama (KF1) dilaksanakan oleh bidan saat ibu nifas masih berada di puskesmas, untuk pelayanan nifas kedua dan ketiga dilaksanakan dengan kunjungan ulang ibu nifas ke puskesmas atau kunjungan rumah oleh bidan desa sesuai dengan jadual, namun hal tersebut belum dilaksanakan secara optimal.

Bidan dalam pelaksanaan pelayanan nifas belum sesuai Standar Operasional Prosedur (SOP), dan semua bidan belum lengkap dalam memberikan pelayanan nifas yang terdiri dari identifikasi dan analisis masalah meliputi pengkajian data subyektif dan obyektif, perumusan diagnosa sudah dilaksanakan, penyusunan rencana belum maksimal hanya berdasarkan keluhan pasien, pelaksanaan tindakan sudah dilaksanakan berdasarkan keluhan, belum semua bidan melakukan evaluasi, konseling tentang masa nifas hanya diberikan secara umum. Hal ini tidak sesuai dengan hasil penelitian Roberts dan Prevost bahwa mutu layanan kesehatanadalah terkait dimensi kesesuaian pelayanan kesehatan yang dilaksanakan dengan perkembangan IPTEK serta otonomi profesi dalam menyelenggarakan layanan kesehatan sesuai kebutuhan pasien ${ }^{17}$. Belum semua bidan melakukan pencatatan di register pemeriksaan ibu nifas maupun rekam medik, juga dicatat di buku KIA pasien, hal ini tidak sesuai dengan manajemen kebidanan yang harus melakukan dokumentasi setelah melakukan pelayanan kebidanan. ${ }^{11}$

Tidak ada dukungan dana transportasi kunjungan nifas ke rumah pasien, belum ada pembinaan atau pengawasan yang intensif dari bidan koordinator, kepala puskesmas maupun Dinas Kesehatan terhadap pelaksanaan pelayanan nifas hal ini diketahui ada bidan desa yang tidak mengetahui harus melaksanakan kunjungan rumah ke ibu nifas di wilayahnya.

Bidan ada yang merangkap sebagai bendahara dan pemegang program, hal ini akan menambah beban kerja pegawai bersangkutan yang berpengaruh pada mutu pelayanan kesehatan karena mutu pelayanan kesehatan dipengaruhi oleh jenis, jumlah dan kualifikasi tenaga pelaksana.

Tujuan penelitian ini untuk mengetahui tentang mutu pelayanan nifas pertama (KF1) dan faktor-faktor yang mempengaruhi mutu pelayanan nifas oleh bidan di puskesmas di Kabupaten Pemalang.

\section{METODE PENELITIAN}

Metode penelitian ini adalah kuantitatif dengan desain penelitian crossectional, dilakukan di 14 puskesmas tiap kecamatan di Kabupaten Pemalang pada Bulan Agustus-September 2018. Populasi penelitian adalah semua bidan PNS puskesmas di wilayah Kabupaten Pemalang berjumlah 360 orang. Besar sampel menggunakan rumus minimal sampel size diperoleh jumlah sampel 100 responden yang memenuhi kriteria inklusi (bersedia menjadi responden, PNS dan masa kerja minimal 3 tahun, pendidikan minimal D3 kebidanan) dan kriteria eksklusi (sedang cuti/mengikuti pendidikan/sedang sakit). Penentuan sampel dengan proportional random sampling pada setiap puskesmas terpilih, kemudian di random sampai jumlah terpenuhi.

Data dikumpulkan dengan kuesioner untuk memperoleh data karakteristik bidan dan variabel 
independen (motivasi, imbalan, supervisi dan beban kerja) dan pengamatan / observasi dengan daftar tilik pelayanan nifas (KF1) untuk mengetahui mutu pelayanan nifas pertama (KF1).

Analisis data secara univariat untuk mengetahui distribusi frekuensi dan proporsi. Analisis bivariat untuk mengetahui hubungan antara variabel independen dan variabel dependen. Kemaknaan hubungan menggunakan nilai $p$ value 0.05 bila $p$ value $\leq 0,05$ artinya ada hubungan yang bermakna. Analisis multivariat untuk menganalisis pengaruh variabel bebas secara bersama-sama terhadap variabel terikat, menggunakan analisis multiple regresi logistik.

\section{HASIL DAN PEMBAHASAN}

Berdasarkan hasil penelitian diperoleh data:

Tabel 1. Distribusi Frekuensi Kategori Variabel Independen dan Dependen

\begin{tabular}{|c|c|c|c|}
\hline No. & Variabel & $\begin{array}{c}\text { Jumlah } \\
(\mathrm{n}=100)\end{array}$ & $\begin{array}{c}\text { Persentase } \\
(\%)\end{array}$ \\
\hline 1 & $\begin{array}{l}\text { Mutu pelayanan nifas } \\
\text { (KF1): } \\
-\quad \text { Kurang } \\
-\quad \text { Baik }\end{array}$ & $\begin{array}{l}53 \\
47\end{array}$ & $\begin{array}{l}53,0 \\
47,0\end{array}$ \\
\hline 2 & $\begin{array}{l}\text { Motivasi : } \\
-\quad \text { Kurang } \\
-\quad \text { Baik }\end{array}$ & $\begin{array}{l}54 \\
46\end{array}$ & $\begin{array}{l}54,0 \\
46,0\end{array}$ \\
\hline 3 & $\begin{array}{l}\text { Imbalan : } \\
\text { - } \quad \text { Kurang } \\
\text { - } \quad \text { Baik }\end{array}$ & $\begin{array}{l}65 \\
35\end{array}$ & $\begin{array}{l}65,0 \\
35,0\end{array}$ \\
\hline 4 & $\begin{array}{l}\text { Supervisi : } \\
-\quad \text { Kurang } \\
-\quad \text { Baik }\end{array}$ & $\begin{array}{l}50 \\
50\end{array}$ & $\begin{array}{l}50,0 \\
50,0\end{array}$ \\
\hline 5 & $\begin{array}{l}\text { Beban kerja } \\
\text { - } \quad \text { Sesuai standar } \\
\text { - } \quad \text { Melebihi standar }\end{array}$ & $\begin{array}{l}51 \\
49\end{array}$ & $\begin{array}{l}51 \% \\
49 \%\end{array}$ \\
\hline
\end{tabular}

Tabel 2.Hasil Analisis Bivariat Variabel Independen dengan Variabel Dependen

\begin{tabular}{|c|c|c|c|c|c|c|c|}
\hline \multirow{3}{*}{ Variabel } & \multicolumn{4}{|c|}{$\begin{array}{c}\text { Mutu Pelayanan Nifas } \\
\text { Pertama (KF1) }\end{array}$} & \multirow{2}{*}{\multicolumn{2}{|c|}{ Total }} & \multirow[t]{3}{*}{ P value } \\
\hline & \multicolumn{2}{|c|}{ Kurang } & \multicolumn{2}{|c|}{ Baik } & & & \\
\hline & $\mathbf{n}$ & $\%$ & $\mathbf{n}$ & $\%$ & $\mathbf{n}$ & $\%$ & \\
\hline \multicolumn{8}{|l|}{ Motivasi : } \\
\hline - Kurang & 35 & 64,8 & 19 & 35,2 & 54 & 100 & 0,018 \\
\hline - Baik & 18 & 39,1 & 28 & 60,9 & 46 & 100 & \\
\hline \multicolumn{8}{|l|}{ Imbalan : } \\
\hline - Kurang & 42 & 64,6 & 23 & 35,4 & 65 & 100 & 0,003 \\
\hline - Baik & 11 & 31,4 & 24 & 68,6 & 35 & 100 & \\
\hline \multicolumn{8}{|l|}{ Supervisi : } \\
\hline - Kurang & 30 & 60,0 & 20 & 40,0 & 50 & 100 & 0,229 \\
\hline - Baik & 23 & 46,0 & 27 & 54,0 & 50 & 100 & \\
\hline \multicolumn{8}{|l|}{ Beban kerja } \\
\hline $\begin{array}{l}\text { - Sesuai } \\
\text { standar }\end{array}$ & 29 & 50,9 & 28 & 49,1 & 57 & 100 & 0,774 \\
\hline $\begin{array}{l}\text { - Melebihi } \\
\text { standar }\end{array}$ & 24 & 55,8 & 19 & 44,2 & 43 & 100 & \\
\hline
\end{tabular}

Tabel 3. Hasil Analisis Multivariat Regresi Logistik Faktor yang Berpengaruh terhadap Mutu Pelayanan Nifas Pertama (KF1)

\begin{tabular}{lcccc}
\hline \multirow{2}{*}{ Variabel } & $p$ value & OR & \multicolumn{2}{c}{$95,0 \%$ CI Exp $(\beta)$} \\
\cline { 3 - 5 } & & & Lower & Upper \\
\hline Motivasi & 0,819 & 0,887 & 0,316 & 2,485 \\
Imbalan & 0,031 & 3,466 & 1,122 & 10.710 \\
Supervisi & 0,690 & 1,204 & 0,484 & 2,992 \\
Konstant & & & & \\
a -0,637 & & & & \\
\hline
\end{tabular}

Analisis Univariat :

Dari tabel 1 diketahui mutu pelayanan nifas pertama (KF1) kurang $53 \%$, motivasi kurang 54\%, Imbalan kurang 65\%, supervisi kurang dan baik masing-masing $50 \%$, beban kerja sesuai standar 51\%.

Gambaran mutu pelayanan nifas pertama (KF1), berdasarkan hasil kuesioner dan observasi yang dilakukan oleh bidan yang ditunjuk sebagai enumerator didapatkan bahwa mutu pelayanan nifas pertama (KF1) oleh bidan di puskesmas kurang yaitu sebesar 53\%, rata-rata mutu pelayanan nifas pertama (KF1) sebesar 72,22 dengan nilai median 73,50 , skor terendah 49 dan skor tertinggi 80. Hal ini menunjukkan bahwa kepatuhan 
bidan di puskesmas dalam melaksanakan pelayanan nifas pertama (KF1) sesuai dengan standar operasional prosedur masih kurang dan perlu ditingkatkan untuk membantu proses pemulihan ibu nifas, deteksi dini, penanganan dan rujukan komplikasi yang dapat terjadi pada masa nifas sehingga dapat menurunkan angka kesakitan dan kematian ibu.

Menurut Bari bahwa mutu merupakan kepatuhan terhadap standar yang sudah ditetapkan, menurut batasan mutu pelayanan yang menunjuk pada tingkat kesempurnaan pelayanan bahwa untuk melindungi pemakai jasa pelayanan kesehatan maka ditetapkan upaya untuk kepuasan pasien sesuai kode etik dan standar pelayanan kesehatan profesi, jadi walaupun pelayanan memuaskan pasien jika pelayanan tidak sesuai kode etik dan standar pelayanan profesi maka tidak termasuk pelayanan kesehatan yang bermutu. ${ }^{17}$ Sedangkan menurut Walyani dkk bahwa mutu juga merupakan tingkat kesempurnaan dan standar yang sudah ditetapkan dalam pelaksanaan pelayanan kebidanan untuk mengurangi tingkat kematian. ${ }^{18}$

Berdasarkan penelitian yang dilakukan oleh Herlina Susmaneli bahwa semakin tidak baik persepsi responden terhadap mutu bukti langsung pelayanan kebidanan, maka responden semakin tidak puas terhadap layanan kebidanan. ${ }^{19}$ Menurut penelitian yang dilakukan oleh Felix Sayinzoga di Rwanda bahwa kegawatan maternal sering terjadi hal ini harus ada perbaikan mutu manajemen kasus dan kunjungan ibu hamil untuk menurunkan angka kesakitan dan kematian ibu. $^{20}$

1. Analisis variabel yang berhubungan dengan mutu pelayanan nifas pertama (KF1) :

a. Hubungan Motivasi dengan Mutu Pelayanan Nifas Pertama (KF1).

Hasil univariat menunjukkan bahwa sebagian besar bidan memiliki motivasi kurang (54\%), sedangkan hasil analisis bivariat $(p$-value $=0,018)$ menunjukkan ada hubungan yang bermakna antara motivasi dengan mutu pelayanan nifas pertama. Hal ini dapat dikarenakan berdasarkan jawaban di kuesioner bahwa kepala puskesmas tidak membagikan tugas secara merata pada semua bidan (6\%), dapat juga karena ada yang merasa tidak mendapat dukungan dari teman sejawat dalam melaksanakan pelayanan nifas pertama (KF1) (2\%). Hal ini seperti pendapat Keith Davis dalam A.A Anwar Prabu Mangkunegara bahwa pimpinan maupun karyawan yang bersikap positif pada situasi kerjanya (hubungan kerja, fasilitas kerja, iklim kerja, kondisi kerja, pola dan kebijakan pimpinan) akan menunjukkan motivasi kerja tinggi, dan jika bersikap negatif terhadap situasi kerjanya akan menunjukkan motivasi kerja rendah.

Teori motivasi menurut Abraham Maslow menekankan pada faktor yang membuat pegawai melakukan tindakan, sedangkan menurut teori David Mc. Clelland tidak hanya menekankan pada faktor yang membuat pegawai bertindak tetapi juga bagaimana pegawai termotivasi dan menurut teori Skinner menekankan pada faktor yang dapat meningkatkan atau mengurangi suatu tindakan. ${ }^{15}$ Hal ini memiliki arti bahwa pegawai yang memiliki motivasi berprestasi tinggi akan mencapai kinerja tinggi, sedangkan pegawai dengan kinerja rendah dikarenakan motivasi kerjanya rendah.

Hasil penelitian ini sejalan dengan penelitian Usman bahwa ada hubungan antara motivasi dengan kinerja karena motivasi dapat mendorong dan mengarahkan perilaku tenaga kesehatan yang dibuktikan dengan tingkat kedisiplinan yang tinggi dan kemampuan untuk menyelesaikan semua pekerjaan dengan baik. ${ }^{21}$ Penelitian ini juga sejalan dengan penelitian Widiastuti bahwa kinerja baik akan ditampilkan oleh bidan dengan motivasi kerja tinggi, sedangkan kinerja kurang baik akan ditampilkan oleh bidan dengan motivasi kerja rendah. 
b. Hubungan Imbalan dengan Mutu Pelayanan Nifas Pertama (KF1).

Hasil univariat menunjukkan bahwa sebagian besar bidan memiliki imbalan kurang (65\%). Sedangkan hasil analisis bivariat $(p$-value $=0,003)$ menunjukkan ada hubungan yang bermakna antara imbalan dengan mutu pelayanan nifas pertama. Suatu organisasi memakai imbalan untuk menarik serta mempertahankan pegawai dan memotivasinya untuk mencapai tujuan pribadi maupun organisasi. Menurut teori Gibson bahwa sasaran utama imbalan adalah menarik pegawai yang berkualitas untuk bergabung dalam suatu organisasi, mempertahankan pegawai agar tetap bekerja dan memotivasi pegawai agar mencapai prestasi kerja yang tingg. ${ }^{16}$ Hasil penelitian ini sejalan dengan penelitian Subekti bahwa ada hubungan antara imbalan dengan kinerja karena imbalan penting untuk ditunjukkan dan dijelaskan, imbalan berupa penghargaan untuk melanjutkan pendidikan dan juga porsi imbalan disesuaikan dengan beban kerja pegawai sehingga dapat meningkatkan kinerja pegawai. ${ }^{22}$

c. Hubungan Supervisi dengan Mutu Pelayanan Nifas Pertama (KF1).

Hasil univariat menunjukkan bahwa supervisi menurut bidan terhadap pelaksanaan pelayanan nifas pertama (KF1) sama besar antara yang memiliki supervisi kurang $(50 \%)$ dan supervisi baik (50\%), sedangkan hasil analisis bivariat ( $p$-value $=$ $0,229)$ menunjukkan tidak ada hubungan yang bermakna antara supervisi dengan mutu pelayanan nifas pertama. Hal ini bisa dikarenakan pelaksanaan supervisi yang dilakukan baik oleh bidan koordinator, kepala puskesmas maupun Dinas Kesehatan belum dilaksanakan secara rutin dan terjadual dengan baik, padahal menurut Permenkes nomor 75 Tahun 2014 tentang Puskesmas perlu adanya supervisi yang rutin oleh kepala puskesmas maupun Dinas Kesehatan untuk memberikan bimbingan, memelihara disiplin kerja, meningkatkan sistim rujukan/konsultasi dari staf serta melimpahkan pengetahuan dan keterampilan serta fungsi puskesmas untuk melaksanakan pembinaan teknis.

Hasil penelitian ini tidak sejalan dengan penelitian Guspianto bahwa ada pengaruh antara supervisi dengan kepatuhan bidan terhadap standar Antenatal Care (ANC), supervisi merupakan proses pengamatan dari seluruh kegiatan organisasi untuk menjamin bahwa pekerjaan yang dilakukan sesuai dengan rencana, dengan mengamati, memberikan saran dan masukan, serta membandingkan pelaksanaan dengan rencana dan melakukan koreksi jika terjadi penyimpangan. Penelitian ini juga membuktikan bahwa semakin baik supervisi yang dilakukan oleh puskesmas akan berdampak pada meningkatnya kepatuhan bidan terhadap standar pelayanan. Hasil ini juga tidak sejalan dengan penelitian oleh Dinas Kesehatan Kabupaten Muaro yang membuktikan bahwa efektivitas supervisi berpengaruh terhadap kepatuhan dalam menerapkan standar bagi petugas kesehatan di puskesmas, karena semua fungsi manajemen tidak efektif jika tidak ada fungsi supervisi dan salah satu dari pendekatan penerapan mutu adalah dengan pengawasan atau supervisi. ${ }^{23}$

d. Hubungan Beban Kerja dengan Mutu Pelayanan Nifas Pertama (KF1).

Hasil univariat menunjukkan bahwa sebagian besar bidan memiliki beban kerja sesuai standar (57\%). Sedangkan hasil analisis bivariat ( $p$-value $=$ 0,774 ) menunjukkan tidak ada hubungan yang bermakna antara beban kerja dengan mutu pelayanan nifas pertama. Sedangkan Hal ini mungkin dikarenakan pekerjaan yang harus dilakukan bidan cukup banyak sedangkan waktu yang diperlukan untuk melaksanakan pekerjaan dengan baik sesuai dengan SOP yang ada cukup lama, sehingga banyak bidan yang bekerja melebihi waktu efektif bekerja sesuai Permenkes nomor 53 Tahun 2012 tentang Pedoman Pelaksanaan Analisis Beban 
Kerja di Lingkungan Kementerian Kesehatan.

Hasil penelitian ini tidak sejalan dengan penelitian Wawan Setiawan bahwa persepsi responden terhadap beban kerja serta kinerjanya kurang baik lebih besar dibandingkan dengan persepsi responden yang memiliki persepsi terhadap beban kerja kurang baik serta kinerja yang baik. Terdapat kecenderungan responden yang mempunyai kinerja kurang baik mempunyai persepsi kurang baik juga terhadap beban kerja. Ruhimat menyatakan beban kerja mengandung konsep penggunaan energi pokok dan energi cadangan yang tersedia, suatu tugas akan dipandang berat apabila energi pokok telah habis dipakai dan masih harus menggunakan energi cadangan untuk menyelesaikan tugas lain. ${ }^{24}$

Analisis Multivariat

Berdasarkan Tabel 3 dari analisis multivariat ternyata variabel yang berhubungan bermakna dengan mutu pelayanan nifas adalah variabel imbalan dengan p-value 0,031 (pvalue $<0,05$ ). Hasil analisis didapatkan Odds Ratio (OR) dari variabel imbalan adalah 3,466 artinya bidan yang memiliki imbalan baik akan memiliki peluang 3,466 kali untuk melaksanakan pelayanan nifas pertama (KF1) baik dibandingkan bidan yang memiliki imbalan kurang.

\section{KESIMPULAN}

Mutu pelayanan nifas pertama (KF) oleh bidan di puskesmas di Kabupaten Pemalang masih dikatakan belum optimal. Hasil uji analisis multivariat faktor yang berpengaruh terhadap mutu pelayanan nifas pertama adalah variabel imbalan dengan $p$-value $=0,031$ dan $\mathrm{OR}=3,466$ artinya bidan yang memiliki imbalan baik akan memiliki peluang 3,466 kali untuk melaksanakan pelayanan nifas pertama (KF1) baik dibandingkan bidan yang memiliki imbalan kurang.

Untuk meningkatkan mutu pelayanan nifas pertama (KF1) dihimbau agar bidan lebih optimal dalam memberikan asuhan nifas dan pendidikan kesehatan, kepala puskesmas dapat membagi tugas secara merata kepada semua bidan, bidan dalam bekerja menciptakan sikap positif, kepala puskesmas memberikan pujian atas keberhasilan pelayanan nifas, kepala puskesmas dapat mengalokasikan dana transportasi kunjungan rumah, pelaksanaan supervisi dilaksanakan terjadual dan rutin pada semua bidan.

\section{DAFTAR PUSTAKA}

1. Ermalena, M. Indikator Kesehatan SDGs di Indonesia. in (2017).

2. Dinas Kesehatan Provinsi Jawa Tengah. Profil Kesehatan Provinsi Jawa Tengah Tahun 2015. (2015).

3. Dinas Kesehatan Provinsi Jawa Tengah. Profil Kesehatan Provinsi Jawa Tengah Tahun 2016. 3511351, (2016).

4. Dinas Kesehatan Kabupaten Pemalang. Profil Kesehatan Kabupaten Pemalang Tahun 2015. (2015).

5. Dinas Kesehatan Kabupaten Pemalang. Profil Kesehatan Kabupaten Pemalang Tahun 2016. (2016).

6. Bidang Kesmas Dinas Kesehatan Kabupaten Pemalang. Rekapitulasi Data Kematian Ibu Kabupaten Pemalang. (2017).

7. Bidang Kesmas Dinas Kesehatan Kabupaten Pemalang. Laporan Seksi Ibu dan Bayi Bidang Kesmas Kabupaten Pemalang. (2017).

8. WHO. Postpartum Care of the Mother and Newborn: practical guide. (1998).

9. Achyar, K. \& Rofiqoh, I. Pengaruh Kunjungan Nifas Terhadap Komplikasi Masa Nifas di Wilayah Puskesmas Sokaraja 1 Kabupaten Banyumas. Medisains XIV, 59-64 (2016).

10. Departemen Kesehatan. Pedoman Pemantauan Wilayah Setempat 
Kesehatan Ibu dan Anak (PWS-KIA). (Dirjen Binkesmas, 2009).

11. Farodis, Z. Panduan Lengkap Manajemen Kebidanan. (D-Medika, 2012).

12. Dinas Kesehatan Kabupaten Pemalang. Pencapaian Standar Pelayanan Minimal Bidang Kesehatan Kabupaten PemalangTahun 2017. (2017).

13. Ghufron, M. Strategi Terkini Peningkatan Mutu Pelayanan Kesehatan Konsep dan Implementasi. (Magister Kebijakan Pembiayaan dan Manajemen Asusransi/Jaminan Kesehatan FK UGM, 2008).

14. Pohan, I. Jaminan Mutu Layanan Kesehatan. (Penerbit Buku Kedokteran EGC, 2006).

15. Mangkunegara, A. Evaluasi Kinerja SDM. (PT Refika Aditama, 2017).

16. Ivancevich, D. \& Gibson. Organisasi : Perilaku, Struktur dan Proses. (Erlangga, 2017)

17. Bari, S. Buku Panduan Praktis Pelayanan Kesehatan Maternal dan Neonatal. (Yayasan Bina Pustaka Sarwono Prawiroharjo, 2002).

18. Walyani, E. \& Purwoastuti, E. Mutu Pelayanan Kesehatan dan Kebidanan. (PUSTAKABARUPRESS, 2015).

19. Susmaneli, H. \& Triana, A. Dimensi Mutu Pelayanan Kebidanan terhadap Kepuasan Pasien Program Jampersal. J. Kesehat. Masy. Nas. 8, 418-422 (2014).

20. Sayinzoga, F., Bijlmakers, L., Velden, K. \& Dillen, J. Severe maternal outcomes and quality of care at district hospitals in Rwanda - a multicentre prospective case-control study. BMC Pregnancy Childbirth 17, 1-9 (2017).

21. Usman. Analisis Kinerja Tenaga Kesehatan pada Puskesmas Lapadde Kota Parepare. J. MKMI 12, 21-28 (2016).

22. Subekti, S., Widagdo, L. \& Wulan,
L. Faktor-faktor yang Mempengaruhi Kinerja Bidan Desa dalam Penerapan Standar Asuhan Kebidanan Ibu Bersalin di Kabupaten Semarang. J. Manaj. Kesehat. Indones. 2, 116-122 (2014).

23. Dinas Kesehatan Kabupaten Muaro. Bidang Perencanaan. Determinan Kepatuhan Bidan di Desa terhadap Standar Antenatal Care Determinants of Village Midwives Compliance towards Antenatal Care. 69-75 (2008).

24. Setiawan, W. Beberapa Faktor yang Berhubungan dengan Kinerja Bidan di Desa dalam Pertolongan Persalinan di Kabupaten Tasikmalaya. (Universitas Diponegoro, 2007). 
